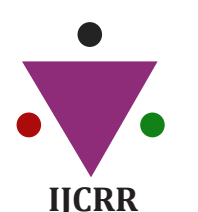

IJCRR

Section: Healthcare Sci. Journal Impact Factor: 6.1 (2018) ICV: 90.90 (2018)

(c) (7) (8) Copyright@IJCRR

\section{Role of Diffusion-Weighted MRI Imaging in Diagnosing Malignancy in Patients with Thick Wall Gallbladder}

\author{
Manas Agarwal ${ }^{1}$, Anu Behari ${ }^{2}$, Ashok Kumar ${ }^{3}$, V. K. Kapoor' ${ }^{2}$, Rajnikant Yadaw ${ }^{4}$ \\ 'MS, Senior Resident, Department of Surgical Gastroenterology, Sanjay Gandhi Postgraduate Institute of Medical Science, Lucknow, 22601, \\ India; 'MS, Professor, Department of Surgical Gastroenterology, Sanjay Gandhi Postgraduate Institute of Medical Science, Lucknow, \\ 226014, India; ${ }^{3}$ MS, Associate Professor, Department of Surgical Gastroenterology, Sanjay Gandhi Postgraduate Institute of Medical \\ Science, Lucknow, 226014, India; ${ }^{\mathrm{M} M S}$, Additional Professor, Department of Radiology, Sanjay Gandhi Postgraduate Institute of Medical \\ Science, Lucknow, 226014, India.
}

\title{
ABSTRACT
}

Objectives: Thick wall gallbladder (TWGB) is difficult to characterize on conventional imaging. Here we study the role of diffusion-weighted MRI in distinguishing between benign and malignant causes of TWGB.

Methods: In this prospective study, we evaluated 25 patients with TWGB (>3mm wall thickness) on ultrasound. Diffusion-weighted MRI was done with the calculation of apparent diffusion coefficient (ADC) values. Patients were subjected to an appropriate surgical procedure. MRI findings were compared with histopathological reports.

Results: Mean age was 48.52 $\pm 9.6 y r s(30-68 y r s)$ with F: M ratio of 2.1:1. MRI showed diffusion restriction in 16 (64\% patients), the breach in mucosal continuity in $13(52 \%)$, and GB wall thickening in $20(80 \%)$. MRI reported carcinoma in 12 (48\%), cholecystitis in 11 (44\%), and xanthogranulomatous cholecystitis (XC) in 2 (8\%). Histopathology reports (available for 24 patients who were operated) revealed adenocarcinoma in $6, \mathrm{XC}$ in 7 , and cholecystitis in 11 patients. Diffusion restriction and absence of GB calculi were seen to be significantly related to malignancy. The sensitivity was $100 \%$ and specificity $88.9 \%$ for differentiating between carcinoma and cholecystitis. Overall, DWI-MRI had the sensitivity and negative predictive value of $100 \%$ each, the specificity of $66.67 \%$, the positive predictive value of only $50 \%$, and an accuracy of $75 \%$.

Conclusion: Diffusion-weighted MRI is a useful imaging modality for the characterization of thick wall GB when used with quantitative assessment of ADC values. It could help to diagnose the presence of malignancy in doubtful cases.

Key Words: Thick Wall Gall Bladder, Diffusion-Weighted MRI, Carcinoma Gall Bladder.

\section{INTRODUCTION}

Introduction: Gallbladder cancer (GBC) is the most common cancer of the biliary tract. In north India, it is the commonest gastrointestinal cancer in females and $3 \mathrm{rd}$ most common cause of cancer deaths in women. ${ }^{1}$ Most patients with GBC have advanced disease at presentation and thus $5 \mathrm{yr}$ survival rate is $<5 \%$ in most series. Prognosis and survival related to the stage. Thus, early and accurate diagnosis is important to prevent delayed treatment. GBC presenting as wall thickening is seen in $20-30 \%$ of cases. ${ }^{2}$ Wall thickening could also be seen in certain benign conditions e.g. xanthogranulomatous cholecystitis, which could be easily managed by laparoscopic cholecystectomy. ${ }^{3}$ most of the time it could be difficult to differentiate from malignancy. Transabdominal sonography (USG) is the first imaging examination performed because of its low cost, non-invasiveness and widespread availability. Although USG has a high sensitivity for detecting tumours at advanced stages, however, have some limitations. ${ }^{4} \mathrm{CT}$ and MRI have been widely used for the diagnostic dilemma. A contrast-enhanced computed tomography (CECT) scan is the recommended diagnostic modality following suspicion of GBC on USG. But the value of CT in differentiating between benign and malignant GB wall thickening is limited. ${ }^{5}$ There for there is a need for better or an additional imaging modality. ${ }^{6}$ Magnetic resonance imaging (MRI) has been introduced to characterize GBC. GBC is typically T1

\section{Corresponding Author:}

Dr. Ashok Kumar, MS, Associate Professor, Department of Surgical Gastroenterology, Sanjay Gandhi Postgraduate Institute of Medical Science, Lucknow, 226014, India; Email: drashok97@gmail.com

ISSN: 2231-2196 (Print)

Received: 03.06 .2020
ISSN: 0975-5241 (Online)

Revised: 23.07 .2020
Accepted: 18.08 .2020
Published: 22.09 .2020 
hypointense and $\mathrm{T} 2$ hyper intense. It shows enhancement after contrast administration. Malignancy exhibits strong and rapid enhancement in the early phase, which persists through the delayed scan, i.e. early and prolonged enhancement. Studies have defined certain MRI features which point to a specific pathology of gallbladder. Presence of diffuse wall thickening, continuous enhancing mucosa line, pericholecystic inflammation and presence of gallbladder stone suggests xanthogranulomatous cholecystitis. On the contrary, disruption of mucosal line, early GB enhancement and no stones is considered as definitive of GBC. ${ }^{7}$ The application of diffusion weighted imaging (DWI) in MRI has been introduced to further improve the diagnostic ability of MRI images. In malignancies, infarction, intracellular portion is increased and diffusion gets restricted, which could be seen as a hyper intensity on DWI images. In addition to hyper intensity on DWI images quantitative evaluation of diffusion restriction can be done by noting value of apparent diffusion coefficient (ADC), which is dependent upon diffusion weighted image intensity and its $b$ value. Both quantitative and qualitative assessment has been showed to better characterize GB lesions before surgery. We designed this study to understand the usefulness of DWI-MRI in diagnosing GB malignancy and correlate the reports with histopathology of patients with thick walled gallbladders of USG.

\section{MATERIALS AND METHODS}

The study comprised a single center, prospective observational study. It was conducted in Department of surgical gastroenterology and department of radiology in a tertiary care referral institute in North India, from September, 2016 to April, 2018. An informed written consent was taken. All the patients presenting to outpatient department of surgical gastroenterology with thick wall gall bladder (wall thickness $>3 \mathrm{~mm}$, TWGB) on ultrasound were included in the study. Patients with upper abdominal symptoms, who, on further workup were found to have TWGB were also included. Patients with a definite mass forming lesion on ultrasound were excluded. And other patients who were found inoperable were due to sever comorbidities and incompatibilities for MRI were excluded. After obtaining routine blood tests along with renal function test, they were subjected to contrast enhanced diffusion restricted MRI, and findings were recorded.

All MRI examinations were performed with a 3.0 T Signa HDxt MRI scanner (GE Healthcare, Milwaukee, WI, USA) with an 8 channel body coil. The scanning sequences were as follows:

- Axial respiratory-triggered T2-weighted fast spinecho (TR/TE/NEX; 3000-5647.1/78.2-81.1/1, 3 mm section thickness, $0 \mathrm{~mm}$ intersection gap, 288X256 matrix, $380 \mathrm{~mm}$ field of view),

- Axial respiratory triggered DWI (diffusion weightings: $b=0 \mathrm{~s} / \mathrm{mm} 2$ and $1000 \mathrm{~s} / \mathrm{mm} 2$, TR/TE/NEX: 705813333/68.1/8, $3 \mathrm{~mm}$ section thickness, $0 \mathrm{~mm}$ intersection gap, 128x128 matrix, $380 \mathrm{~mm}$ field of view)

- Pre and post contrast axial single breath hold 3D spoiled gradient echo sequence with two-point Dixon water-fat separation (LAVA FLEX) (TR/TE/NEX; $4.3 / 2 / 1,3 \mathrm{~mm}$ section thickness, $0 \mathrm{~mm}$ intersection gap, 320x192 matrix, $380 \mathrm{~mm}$ field of view). Gadodiamide (Omniscan; GE Healthcare Medical Diagnostics, Little Chalfont, Buckinghamshire, UK) at a dose of $0.1 \mathrm{mmol} / \mathrm{kg}\{0.2 \mathrm{ml} / \mathrm{kg}\}$ of body weight was used as contrast material.

All DWI images were transferred to an Advantage Workstation 4.4 (GE Healthcare, Milwaukee, WI, USA), at which ADC maps were evaluated. ADC value of the lesion was quantified by manually drawing on the lesion a circular region of interest (ROI) on the ADC map of $(b=1000)$ DWI. Mean ADC was calculated from ROI's at two different locations in the lesion. An expert radiologist with experience in interpreting abdominal imaging was blinded to information of patient's characteristics, symptoms, sonography and CECT findings and histopathological reports.

Surgical procedure: After pre-anaesthetic checkup all 24 patients underwent for surgery. Patients with suspicion of carcinoma were for staging laparoscopy and extended cholecystectomy, cases with low suspicion were taken for anticipatory extended cholecystectomy (cholecystectomy with $2 \mathrm{~cm}$ liver wedge excision, frozen analysis followed by lymphadenectomy only if frozen found to have positive report). ${ }^{8}$ Postoperative management was as per institution's protocol. Patients were discharged after they resumed a normal diet and drains removal. They were followed up with histopathology report in OPD, after 10 days of discharge and findings recorded. The HPE report was correlated with MRI findings.

Statistical Analysis: SPSS version 22 was used for statistical analysis. Fisher's exact test was used to test the association between variables. One way ANOVA test was used to compare between two groups. Receiver operating characteristic (ROC) curves were plotted to discriminate between two groups an area under the curve (AUC) was calculated. The $\mathrm{P}$-value less than 0.05 was considered as significant.

Results: A total of 25 patients were included in the study. The mean age was 48.52 $\pm 9.6 \mathrm{yrs}$ (30-68yrs). 17 (68\%) were female and 8 (32\% were males). Out of 25 patients, 4 $(16.0 \%)$ did not have any symptoms suspicious of gallbladder disease and were incidentally detected to have TWGB on sonography. 21 patients, $(84.0 \%)$ presented with one or more symptoms. $12(48.0 \%)$ patients had presented with single or recurrent episodes of biliary colic, 4 (16.0\%) had dull aching 
continuous right upper quadrant (RUQ) pain, 1 patient had a history of abdominal lump, 1 patient who presented with jaundice was found to have associated choledocholithiasis, and 3 patients gave the history of anorexia and significant loss of weight.

Examination findings revealed 1 patient having a palpable gallbladder, another one having a palpable gallbladder lump. None of our patients had evidence of advanced malignancy. 1 patient had icterus. All the patients were subjected to abdominal sonography. All but $3(12.0 \%)$ patients had gall stones, with the majority having multiple stones $(17,68 \%)$. All 25 patients had thickened gallbladder walls, with $8(32 \%)$ patients having focal thickening, and $17(68.0 \%)$ having diffusely thickened walls. Thickening was further categorized between patients with wall thickness $3-7 \mathrm{~mm}$ (19 patients, $76 \%$ ) and patients with wall thickness $>7 \mathrm{~mm}$ (6 patients, $24 \%)$.

Out of 24 operated patients, USG suggested GB carcinoma in 11 patients out of which only 4 were found to have malignancy. USG had the sensitivity of $66.67 \%$, the specificity of $61.11 \%$, the positive predictive value of $36.36 \%$ and negative predictive value of $84.62 \%$.

16 of our patients had undergone a contrast-enhanced CT scan. Out of 16, CECT revealed GB mass in $6(24 \%)$ patients. $3(12.0 \%)$ patients had focal wall thickening and $6(24 \%)$ patients had diffuse wall thickening. 1 patient did not have any wall thickening. None had evidence of distant metastasis in the form of liver nodules, peritoneal dissemination, para-aortic or other distant lymph nodes, and ascites. Out of a total 16 patients, malignancy was reported in 7 $(43.75 \%)$ while others were reported to have benign aetiology $(9,56.25 \%)$. In our study, CECT had high sensitivity and negative predictive value ( $83.33 \%$ and $88.89 \%$ respectively), although specificity was $80.00 \%$ and the positive predictive value was $71.43 \%$.

All 25 of our patients underwent diffusion restricted MRI as per our study protocol. Diffusion restriction was found in 16 (64.0\%) patients while in $9(36.0 \%)$, no restriction was present. Gall bladder calculi were present in $22(88 \%)$ patients, and $3(12 \%)$ patients did not have calculi in GB. Out of 22 , $9(40.91 \%)$ had solitary GB calculus impacted at the neck and $13(59.10 \%)$ had multiple GB calculi. 13 (52\%) patients had a breach in the continuity of the GB wall. MRI showed wall thickening in $20(80 \%)$ patients, whereas USG showed TWGB in all 25 patients. (Table 1) One of these patients had a history of past cholecystectomy and was having residual $\mathrm{GB}$, which was found to have thickened wall on USG, but on MRI, wall thickness was normal. Two patients had a history of spontaneous passage of stones in the common bile duct. One patient showed focal wall thickening in fundus on USG but MRI, there was no thickening, multiple small polypoidal lesions were seen, which were sent for frozen sec- tion after laparoscopic cholecystectomy, and histopathology was benign. One patient had mild wall thickening on USG $(4.6 \mathrm{~mm})$, which was not found on MRI. Fat saturated images revealed 3 patients having fat in the wall.

ADC values were calculated for the entire group and the mean ADC value was $2.276^{*} 10^{-3}$. Finally, MRI diagnosed $12(48 \%)$ patients having a suspicion of malignancy, 11 (44\%) patients having cholecystitis, and $2(8.0 \%)$ patients with xanthogranulomatous pathology. (Figure 1, 2, 3) Out of 12 patients reported as GBC, only $6(50 \%)$ were found to have GBC on HPE, (Figure 4) although none of the patients $(n=11)$ reported having benign pathology were found to have GBC, suggesting $100 \%$ negative predictive value of MRI while diagnosing GBC. MRI was seen to have a sensitivity of $100 \%$, the specificity of $66.67 \%$, the positive predictive value of only $50 \%$, and an accuracy of $75 \%$. Looking at specific findings of MRI, the breach in mucosal continuity was found in $13(52 \%)$, in whom $4(30.77 \%)$ patients were found to have malignancy while 5 were found to have xanthogranulomatous cholecystitis. ADC values were calculated for 24 patients who were operated, and in whom histopathology reports were available. Mean ADC value was $2.276 \times 10^{-3}$. The mean ADC value for GB malignancy was lower than that of benign diseases. Mean ADC value of 6 patients with GBC was $1.57 \times 10^{-3}$, and the remaining 18 patients were $2.54 \mathrm{X}$ $10^{-3}$. Amongst benign causes $(\mathrm{n}=18)$, xanthogranulomatous cholecystitis $(n=7)$ had lower ADC values as compared to that of chronic cholecystitis $(n=11)$. Mean ADC value for 7 patients with xanthogranulomatous cholecystitis was 1.77 X $10^{-3}$, while that of 11 patients with chronic cholecystitis was $3.02 \times 10^{-3}$ (2.42 X $10^{-3}$ after removing outliers). Mean $\mathrm{ADC}$ values were compared using "One way ANOVA test with multiple comparisons". The comparison reached statistical significance between malignancy and cholecystitis $(\mathrm{p}=0.002)$, and also between xanthogranulomatous vs chronic cholecystitis $(\mathrm{p}=0.023)$. (Table 2)

To define the cutoff values for diagnosing malignancy and xanthogranulomatous cholecystitis, and distinguish each from chronic cholecystitis, ROC curves were plotted after excluding the outliers. For malignancy vs chronic cholecystitis, with the cutoff of $1.94 \times 10^{-3}$, the test reached a sensitivity of $100 \%$ and specificity of $88.9 \%$ (AUC=98.1\%). (Figure 5) For xanthogranulomatous cholecystitis from chronic cholecystitis, with a cutoff of $2.22 \times 10^{-3}$, (Figure 6) the test reached a sensitivity of $100 \%$, and specificity of $56 \%$, however with the cutoff of $2.07 \times 10^{-3}$, sensitivity was $85.7 \%$ and specificity was $66.7 \%$. Surgery was offered to all patients and 24 patients underwent surgery while 1 patient refused surgery due to personal reasons. Thirteen patients were taken up for laparoscopic cholecystectomy, out of which 8 underwent laparoscopic cholecystectomy, GB was sent for the frozen section for 4 patients, in whom malignancy was suspected on the cut section of GB specimen. 3 of these were 
found to have benign disease whereas 1 out of 4 was found to be adenocarcinoma and laparotomy was done. On laparotomy, inter-aortocaval lymph nodes were found enlarged, which were sampled and sent for frozen and reported positive for metastatic deposits. The further procedure was abandoned and the abdomen was closed. One patient underwent laparoscopic subtotal cholecystectomy, leaving part of GB wall on the liver surface (LSC type 1), 4 were converted to open procedure due to unclear calot's triangle anatomy. ${ }^{9}$ Out of these four, 3 patients underwent complete cholecystectomy after conversion to open. One underwent subtotal cholecystectomy (she was found to have impacted calculus at the neck with dense adhesions to the hepatoduodenal ligament, and part of neck of GB was left in situ, while the remaining GB was removed). One patient underwent open cholecystectomy. She had a history of open cholecystectomy and was found to have a residual gallbladder, which was small and contracted. Hence, the open procedure was done and laparoscopy was not attempted.

Nine of our patients were taken up for staging laparoscopy and extended cholecystectomy. 3 underwent extended cholecystectomy with adequate lymphadenectomy. One patient required extended cholecystectomy with extrahepatic biliary tract excision with hepaticojejunostomy (Enlarged lymph nodes in hepatoduodenal ligament densely adherent to CBD). One patient had diffuse peritoneal dissemination and radical surgery was abandoned. One patient underwent cholecystectomy due to low suspicion of malignancy and frozen biopsy was sent, which was reported as benign. Three patients underwent anticipatory extended cholecystectomy, (2 laparoscopic and 1 open). None of them was found to have malignancy on frozen of GB. Hence, lymphadenectomy was not done. Histopathology reports of our study group (24 operated patients) were chronic cholecystitis $(11,45.83 \%)$, xanthogranulomatous cholecystitis 7 (29.17\%), and adenocarcinoma (6, 25\%).

We have correlated each of the symptoms, USG features, and $\mathrm{CT}$ and MRI findings with the pathology reports of our patients. While recording MRI findings, it was seen that absence of calculi in 3 patients were related to malignant pathology. None other features could reach statistical significance. (Table 3)

\section{DISCUSSION}

Gall bladder pathologies are more 2-3 times more commonly found in females that is also reflected from our study (female to male ratio $=2: 1) .{ }^{10}$ As reported, a large majority of gall stones are asymptomatic (70-95\%). ${ }^{11}$ Right upper quadrant pain has been observed to be the most common symptom of gallstone disease, amounting to $95 \%$ of patients. ${ }^{12}$

Abdominal sonography is the gold standard diagnostic imaging modality for gallstones and to diagnosing cholecystitis its sensitivity (80-100\%), specificity (60-100\%) and positive predictive value is $>90 \% .{ }^{13}$ In our study group, ultrasound was able to detect the presence of gallstones in all except one case where MRI revealed the presence of stones while ultrasound showed only wall thickening with no stones. USG revealed focal thickening in 8 patients, which is considered as a marker for malignancy, Out of these 8 patients, 4 were confirmed to have GBC on histopathology of the operated specimen.

CECT scan has been the reference standard for diagnosing and managing suspected GBC patients. It can visualize GB mass, focal or diffuse thickening of GB wall, the extension to surrounding organ, regional or distant lymph nodes and metastasis. Thus, although CECT has a high sensitivity rate for GBC specificity is not high and lots of patients end up having a more radical surgical procedure than required. ${ }^{14}$ In our study, negative predictive value was $188.89 \%$ and the positive predictive value was only $71.43 \%$, which is close to literature data of $89 \%$ and $96 \%$ respectively. The accuracy in our study was $81.25 \%$ while a cross-sectional study in 2016 , reported figures of $93.5 \%$. We did diffusion restriction MRI to better identify patient's disease before surgery. We found that sensitivity and specificity of MRI was respectively $100 \%$ and $66.67 \%$, which is similar to the published data. ${ }^{15,16,17}$ Mean ADC values for GBC was $1.5 \times 10^{-3}$. Several authors have observed the ADC values and cutoff to differentiate between benign and malignant GB lesions. There is yet no accepted cutoff value. In a retrospective study by Yoshioka, et al. the cutoff value of $1.64 \times 10^{-3}$ for GBC vs inflammation was found to have high sensitivity and specificity $\left(86.4 \%\right.$ and $81.8 \%$, respectively. ${ }^{18,19}$

Kim, et al. determined the diagnostic value of diffusionweighted MRI for thick-walled gallbladders. They noted that mean $\mathrm{ADC}$ value for $\mathrm{GBC}$ was $1.46 \times 10^{-3}$, that of benign GB lesions were $2.16 \times 10^{-3}$. Optimal ADC cutoff value of $1.449 \times 10^{-3}$ yields sensitivity for GBC up to $70 \%$, and specificity $97 \%$. Mean ADC values were similar to that of our study ${ }^{3}$.

In another Korean retrospective study of 33 patients by Kang, et al. the cutoff for differentiating xanthogranulomatous and malignant pathology of the gallbladder was taken as $1.52 \mathrm{X}$ $10^{-3}$ which showed an accuracy of $79 \%$, with specificity and positive predictive value of $100 \%$, but the sensitivity of just $50 \%{ }^{7}$. The mean ADC value of xanthogranulomatous lesion was $1.64 \times 10^{-3}$, which is very close to our study $(1.77 \mathrm{X}$ $\left.10^{-3}\right)$. (Table 4)

This study also reported continuity of enhancing mucosal line to be seen more frequently in xanthogranulomatous disease and found it to be statistically significant although in our study, out of 7 patients of xanthogranulomatous pathology, only 2 had mucosal continuity while 5 had a breach in continuity. The fat component in the GB wall was seen in 
3 of our patients, and one of them was found to have xanthogranulomatous pathology. In Kang's study also, only 1 patient had a fat component, out of a total of 14 patients. This suggests fat in the wall is a relatively non-specific finding to diagnose this pathology. Ours is the first prospective study which looks at MRI findings and correlates it with the biopsy report of the surgical specimen.

\section{CONCLUSION}

Gallbladder cancer (GBC) is the most common biliary tract malignancy. Mostly present in advance stage and thus has a poor outcome. Its presentation as thick wall gall bladder is a diagnostic dilemma to differentiated, benign from malignancy. In this scenario, diffusion-weighted MRI could be a useful imaging modality for characterization of thick wall gallbladder, especially when used with quantitative assessment of ADC values. Thus, we would like to conclude that quantitative evaluation of ADC maps is a useful parameter and might improve the specificity of MRI in differentiating benign from malignant gallbladder pathology. However, more prospective studies with larger sample size are required to further implement it into routine practice.

\section{ACKNOWLEDGEMENT}

We wish to acknowledge the immense help received from the scholars whose articles are cited and included in references to this manuscript. The authors are also grateful to authors/editors/publishers of all those articles, journals and books from where the literature for this article has been reviewed and discussed.

\section{Source of Funding: There is no source of funding.}

Conflict of interest: I am declaring that we have no conflict of interests

Informed consent: we have obtained consent from patients or close kin for the images and other clinical information to be reported in the journal. They understand that the names and initials will not be published and due efforts will be made to conceal their identity, but anonymity cannot be guaranteed.

\section{REFERENCES}

1. Dutta U, Nagi B, Garg PK, Sinha SK, Singh K, Tandon RK. Patients with gallstones develop gallbladder cancer at an earlier age. Eur J Cancer Prev 2005; 14:381-385. Pub Med PMID: 16030429

2. Furlan A, Ferris JV, Hosseinzadeh K, Borhani AA. Gallbladder carcinoma update: multimodality imaging evaluation, staging, and treatment options. AJR Am J Roentgenol 2008; 191:14401447. PubMed PMID: 18941083.
3. Kim SJ, Lee JM, Kim H, Yoon JH, Han JK, Choi BI. Role of diffusion-weighted magnetic resonance imaging in the diagnosis of gallbladder cancer. J Magn Reson Imaging 2013; 38:127-137. PubMed PMID: 23281048.

4. Barbosa, Aldo Benjamim Rodrigues, Souza, Luis Ronan Marquez Ferreira de, Pereira, Rogério Silva. Gallbladder wall thickening at ultrasonography: how to interpret it? Radiol Bras 2011; 44:381-387.

5. Tseng JH, Wan YL, Hung CF, Ng KK, Pan KT, Chou AS, et al.. Diagnosis and staging of gallbladder carcinoma. Evaluation with dynamic MR imaging. Clin Imaging 2002; 26:177-182. PubMed PMID: 1983470.

6. Ghafoor N, Abedin N, Mohiuddin AS. Role of ultrasound and computed tomography in the evaluation of gallbladder malignancy. AKMMC J 2017; 8:105-111.

7. Kang TW, Kim SH, Park HJ, Lim S, Jang KM, Choi D, et al.. Differentiating xanthogranulomatous cholecystitis from the wall-thickening type of gallbladder cancer: added value of diffusion-weighted MRI. Clin Radiol 2013; 68:992-1001. PubMed PMID: 3622795.

8. Kapoor VK, Singh R, Behari A, Sharma S, Kumar A, Prakash A, et al.. Anticipatory extended cholecystectomy: the 'Lucknow' approach for thick-walled gall bladder with low suspicion of cancer. Chin Clin Oncol 2016; 5:8. PubMed PMID: 26932432.

9. Dilip Gode, C Palanivelu, Zahiruddin Quazi Syed. New variants of laparoscopic subtotal cholecystectomy in management of acute cholecystitis. International Journal of Medical Science and Public Health 2014; 3:397-400.

10. Sharma A, Sharma KL, Gupta A, Yadav A, Kumar A. Gallbladder cancer epidemiology, pathogenesis and molecular genetics: Recent update. World J Gastroenterol. 2017 Jun 14; 23:39783998. PubMed PMID: 28652652.

11. Behari A, Kapoor VK. Asymptomatic gallstones (AsGS) - To treat or not to?. Indian J Surg. 2012; 74:4-12. Pubmed PMID: 23372301.

12. Vahed LK, Khedmat L. Frequency of symptoms associated with gallstone disease: a hospital-based cross-sectional study. Eur J Transl Mylo 2018; 28:7412. Pubmed PMID: 29991988.

13. Gluskin. Ultrasound of the liver, biliary tract, and pancreas. In: Janargin W, Aleen PJ, Chapman W editors. Blumgart's Surgery of the liver, biliary tract, and pancreas. $6^{\text {th }}$ ed. Philadelphia (PA): Elsevier; 2017. p. 264.

14. Katz SS. Computed tomography of the liver, biliary tract, and pancreas. In: Janargin W, Aleen PJ, Chapman W editors. Blumgart's Surgery of the liver, biliary tract, and pancreas. $6^{\text {th }}$ ed. Philadelphia (PA): Elsevier; 2017. p. 339.

15. Tan CH, Lim KS. MRI of gallbladder cancer. Diagn Interv Radiol 2013;19:312-9. PubMed PMID: 23603123.

16. Baliyan V, Das CJ, Sharma R, Gupta AK. Diffusion-weighted imaging: technique and applications. World J Radiol 2016:8:785798. Pubmed PMID: 27721941.

17. Hagmann P, Jonasson L, Maeder P, Thiran JP, Wedeen VJ, Meuli R. Understanding diffusion MR imaging techniques: from scalar diffusion-weighted imaging to diffusion tensor imaging and beyond. Radiographics 2006;26 Suppl 1:205-23. PubMed PMID: 17050517.

18. Yoshioka M, Watanabe G, Uchinami H, Miyazawa H, Abe Y, Ishiyama K, et al.. Diffusion-weighted MRI for differential diagnosis in gallbladder lesions with special reference to ADC cutoff values. Hepatogastroenterology 2013; 60:692-8. PubMed PMID: 24046830.

19. Irie H, Kamochi N, Nojiri J, Yoshiaki Egashira, Kohei Sasaguri, Sho Kudo. High b-value diffusion-weighted MRI in differentiation between benign and malignant polypoid gallbladder lesions. Acta Radiol 2011; 52:236-40. PubMed PMID: 21498356. 
Table 1: MRI findings of our study group, $\mathrm{N}=25$

\begin{tabular}{ll} 
MRI features & $\begin{array}{l}\text { Number (\%) } \\
{[\mathbf{n = 2 5}]}\end{array}$ \\
- Diffusion restriction & $16(64)$ \\
- GB calculi & \\
0 Solitary calculus impacted at neck & $9(40.91)$ \\
0 Multiple calculi & $13(59.10)$ \\
$\quad$ No calculi & 3 \\
- Breach in mucosal continuity & $13(52)$ \\
- GB wall thickening & $20(80)$ \\
- Fat density in wall & $3(12)$ \\
& \\
Final impression & $11(44)$ \\
- Cholecystitis & $2(8)$ \\
- Xanthogranulomatous cholecystitis & $12(48)$ \\
\hline
\end{tabular}

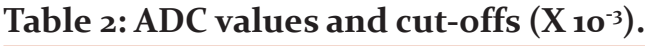

\begin{tabular}{lccc} 
Histopathology & Mean \pm SD & Range & Median \\
Malignancy & $1.57 \pm 0.254$ & $1.29-1.94$ & 1.49 \\
$\begin{array}{l}\text { Xanthogranulomatous } \\
\text { cholecystitis }\end{array}$ & $1.77 \pm 0.327$ & $1.33-2.19$ & 1.75 \\
\begin{tabular}{l} 
Chronic cholecystitis \\
\hline
\end{tabular} & $3.02 \pm 1.495$ & $1.89-6.8$ & 2.53 \\
\hline
\end{tabular}

Table 3: Correlation of MRI findings with histopathology reports. $\mathrm{N}=24$

\begin{tabular}{|c|c|c|c|c|c|}
\hline \multirow{3}{*}{$\begin{array}{l}\mathrm{N}=24 \\
\text { MRI Find- } \\
\text { ings }\end{array}$} & \multicolumn{2}{|c|}{ MRI Finding } & \multicolumn{2}{|c|}{ GBC } & \multirow{3}{*}{$\begin{array}{c}\mathbf{P} \\
\text { value }^{\#}\end{array}$} \\
\hline & \multirow{2}{*}{$\begin{array}{c}\text { Present } \\
(\mathbf{n}, \%)\end{array}$} & \multirow{2}{*}{$\begin{array}{c}\text { Absent } \\
(\mathbf{n}, \%)\end{array}$} & \multicolumn{2}{|c|}{ MRI Finding } & \\
\hline & & & $\begin{array}{c}\text { Yes } \\
(\mathbf{n}, \%)\end{array}$ & $\begin{array}{c}\text { No } \\
(\mathbf{n}, \%)\end{array}$ & \\
\hline $\begin{array}{l}\text { - Diffusion } \\
\text { restriction }\end{array}$ & $15(62.5)$ & $9(37.5)$ & $6(40)$ & o (o) & 0.052 \\
\hline $\begin{array}{l}\text { - Absence of } \\
\text { GB calculi }\end{array}$ & $3(12.5)$ & $21(87.5)$ & $3(100)$ & $3(14.28)$ & 0.009 \\
\hline $\begin{array}{l}\text { - Breach in } \\
\text { mucosal } \\
\text { continuity }\end{array}$ & $13(54.17)$ & $11(45.83)$ & $4(30.77)$ & $2(18.18)$ & 0.649 \\
\hline $\begin{array}{l}\text { - GB wall } \\
\text { thickening }\end{array}$ & $19(79.17)$ & $5(21.83)$ & $6(31.58)$ & $o(0)$ & 0.280 \\
\hline $\begin{array}{l}\text { - Fat density } \\
\text { in wall }\end{array}$ & $3(12.5)$ & $21(87.5)$ & $1(33.33)$ & $(23.81)$ & 1.00 \\
\hline
\end{tabular}

\# Fisher exact test used. P-value equal to 1.o denoted by $>0.05$. $\mathrm{P}<0.05$ significant

*Number and percentage of patients who were suffering from the symptom and found to have GBC

\$ Number and percentage of patients who were not suffering from the symptom and found to have GBC

Table 4: Studies depicting various ADC values and cut-off levels.

\begin{tabular}{|c|c|c|c|c|c|c|}
\hline $\begin{array}{l}\text { Place, year of } \\
\text { study }\end{array}$ & Authors & Type of study & $\mathbf{n}$ & $\mathrm{GBC}^{*}\left(\mathrm{X}^{10-3}\right)$ & $\operatorname{Benign}\left(\mathbf{X}^{10-3}\right)$ & $\begin{array}{l}\text { CUT } \\
\text { off }\left(\mathbf{X}^{10-3}\right)\end{array}$ \\
\hline Japan, $2013^{18}$ & Yoshioka et al. & Retrospective & 40 & 1.31 & 1.97 & 1.64 \\
\hline Korea, $2013^{3}$ & Kim et al. & Retrospective & 75 & 1.46 & 2.16 & 1.45 \\
\hline $2011^{19}$ & Irie et al., 2011 & Retrospective & 30 & 1.34 & 2.26 & $\mathrm{ND}^{\#}$ \\
\hline${ }^{8}$ Korea, $2013^{7}$ & Kang et al., 2013 & Retrospective & 33 & 1.08 & $1.64\left(\right.$ Xantho $\left.^{* *}\right)$ & ND \\
\hline $\begin{array}{l}\text { Current study, } \\
2019\end{array}$ & Manas et al. & Prospective & 25 & 1.57 & $\begin{array}{l}2.42 \text { (Benign) } \\
1.77 \text { (Xantho) }\end{array}$ & 1.94 \\
\hline
\end{tabular}

"Gallbladder carcinoma, ${ }^{* *}$ Xanthogranulomatous cholecystitis, ${ }^{\text {s } C o m p a r i s o n ~ d o n e ~ b e t w e e n ~ G B C ~ a n d ~ X a n t h o, ~ " N o t ~ d e f i n e d . ~}$

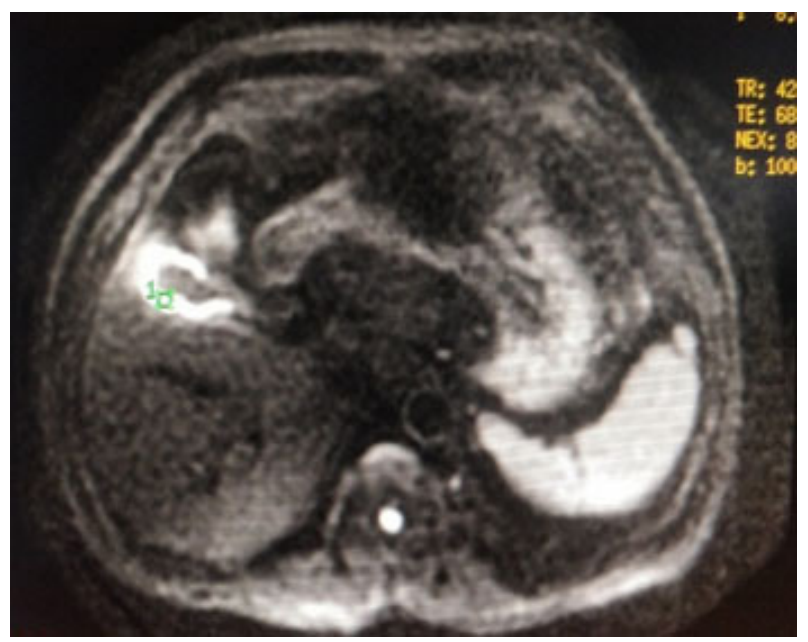

Figure 1: MRI of a patient showing wall thickening in body region.

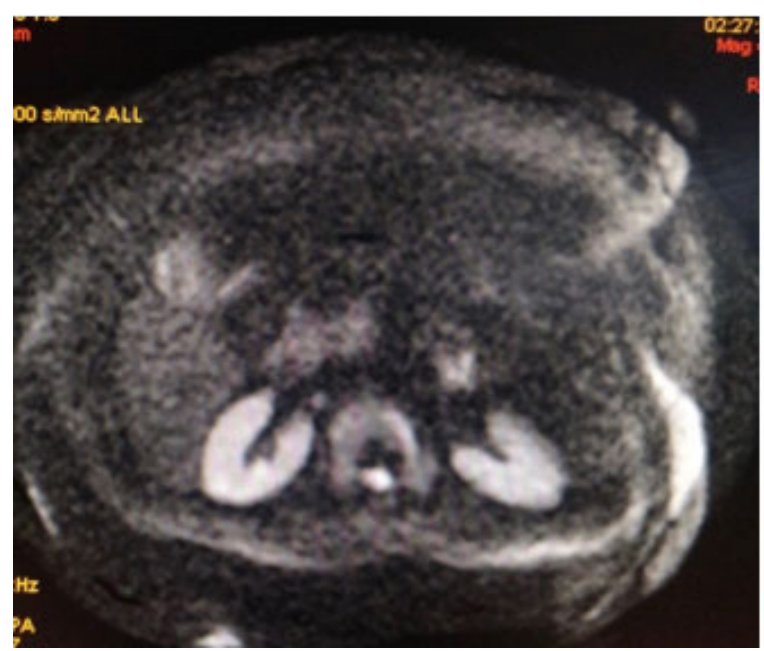

Figure 2: MRI of the same patient showing diffusion restriction $\left(A D C=1.73 \times 10^{-3}\right)$. 


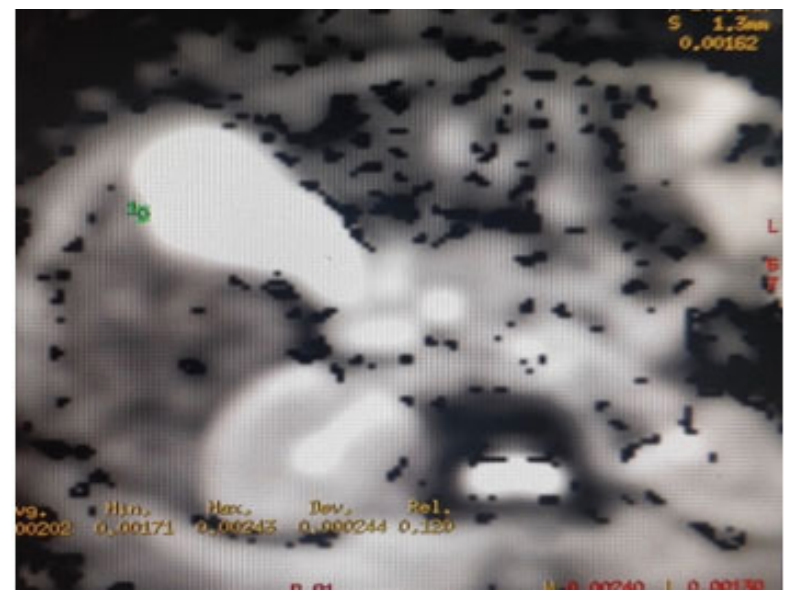

Figure 3: MRI of the same patient showing ADC calculation $\left(1.73 \times 10^{-3}\right)$, [HPE- Xanthogranulomatous cholecystitis].

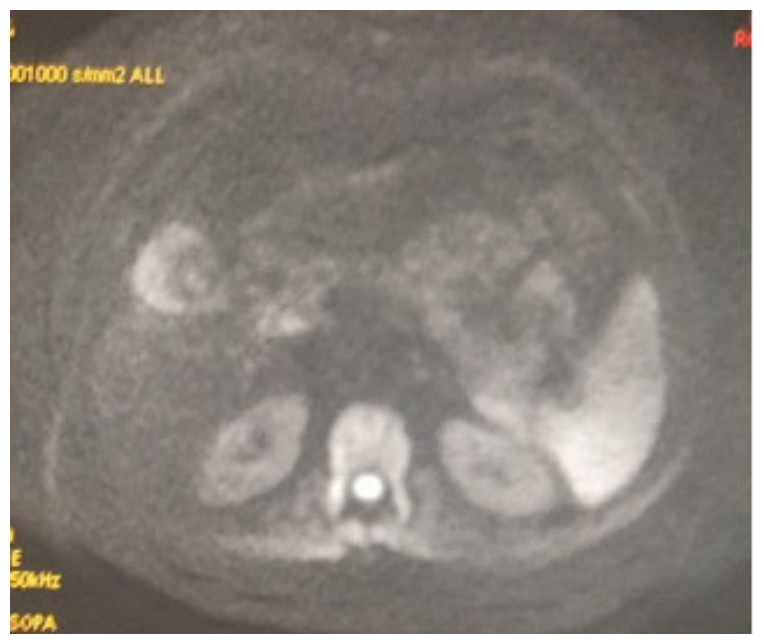

Figure 4: MRI of the same patient showing intense diffusion restriction suggestive of malignancy $\left(A D C=1.77 \times 10^{-3}\right)$, [HPEadenocarcinoma].

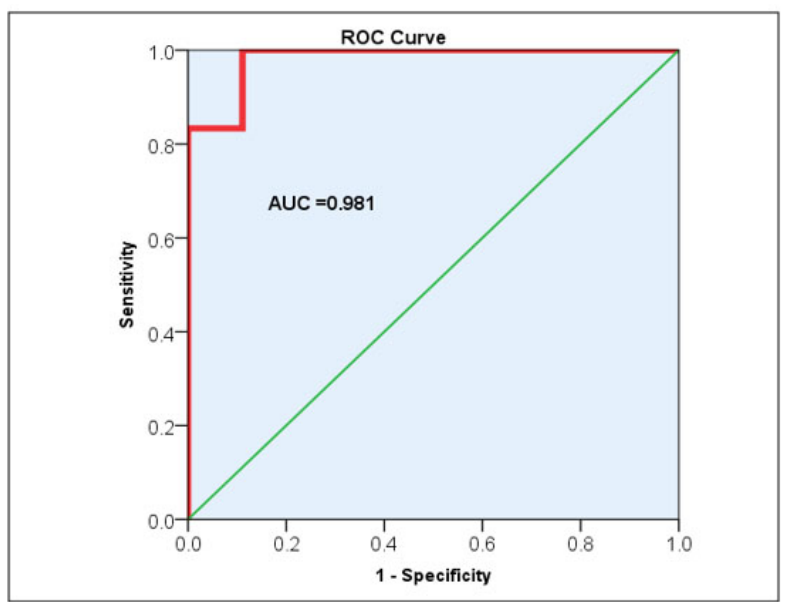

Figure 5: ROC curve for distinguishing malignancy from chronic cholecystitis (Cut-off $=1.94 \times 10^{-3}$ ).

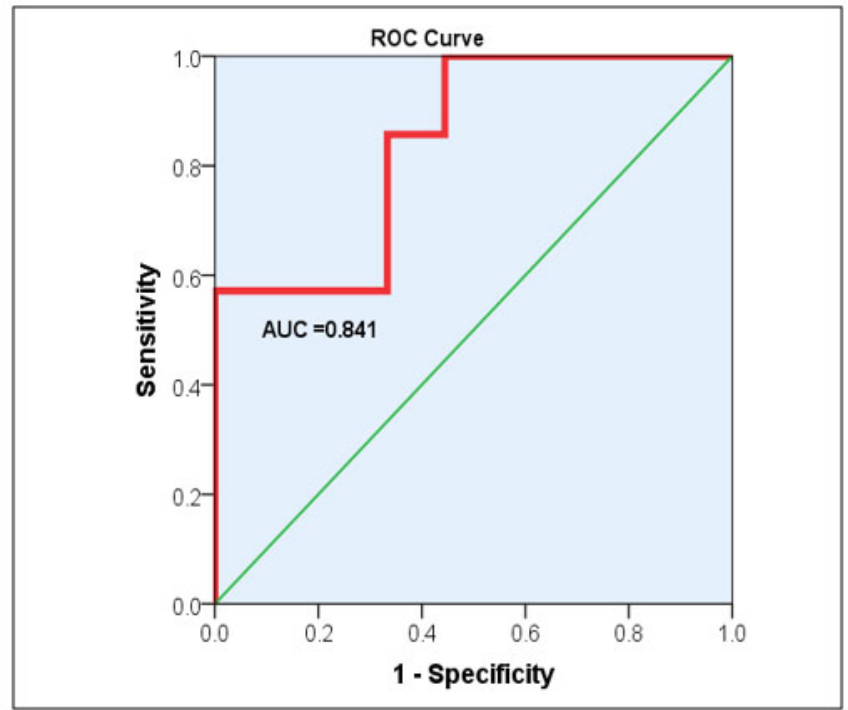

Figure 6: ROC curve for distinguishing xanthogranulomatous from chronic cholecystitis (Cut-off=2.22). 